\title{
Revisiting the Experiential Effect: How Criminal Offending Affects Juveniles' Perceptions of Detection Risk
}

\author{
Florian Kaiser $^{1}\left(\mathbb{D} \cdot\right.$ Björn Huss $^{2} \mathbb{D}$. Jost Reinecke ${ }^{3}$
}

Received: 29 July 2021 / Revised: 11 November 2021 / Accepted: 18 November 2021 /

Published online: 7 December 2021

(c) The Author(s) 2021

\begin{abstract}
Perceptual deterrence research has consistently found that criminal offending is inversely related to subsequent perceptions of the risk of being caught or arrested. This inverse relationship has been dubbed an "experiential effect," reflecting the idea that people learn by committing (undetected) crimes that the detection or arrest risk is lower than first feared. The current study explores the validity of this experiential argument. It relies on self-report data from 3,259 adolescent participants in the panel study Crime in the modern City (Duisburg, Germany). We computed detection rates and risk perceptions, and used fixed effects models to investigate the proposed experiential learning process. Most findings support the experiential argument: (1) juvenile offenses were rarely detected by the police, (2) juveniles (especially those inexperienced with crime) tended to overestimate the detection risk, (3) juveniles reduced their risk perceptions when they committed crimes, (4) this reduction occurred primarily among those who overestimated the detection risk in periods when they were not committing crimes. However, the study also produced the surprising finding that the experiential effect seems to be short-lived: people appeared to return to initial risk perception levels when they stopped committing crimes. Overall, the results corroborate the experiential argument. However, they also indicate that the argument may need revision to account for the potential shortterm nature of the experiential effect. This "ephemerality effect" is good news for policy, as lowered risk perceptions will in most cases only temporarily increase the likelihood of future delinquency.
\end{abstract}

Keywords Deterrence theory $\cdot$ Experiential effect $\cdot$ Naiveté effect $\cdot$ Novelty effect . Detection risk · Risk overestimation

Florian Kaiser

florian.kaiser@uni-muenster.de

Extended author information available on the last page of the article 


\section{Introduction}

The threat of sanctions is omnipresent in modern societies. It is evident in security guards and detectives in stores; police patrolling by foot, car, and bicycle; and video surveillance in public and private spaces. As early as the eighteenth century, Cesare Beccaria (1764/1872) outlined the principles behind the threat of punishment. He argued that if legal agents' punitive reactions to criminal offenses are sufficiently certain, severe, and swift, they will deter both the offenders and other individuals from committing (further) crimes.

In the mid-1970s, research on the mechanisms underlying these basic principles highlighted the importance of individual perceptions in the deterrence process (e.g., Geerken \& Gove, 1975; Waldo \& Chiricos, 1972). Based on the idea that it is solely what individuals perceive in a given situation that guides their actions, this research suggested that the legal (threat of) punishment can only prevent crimes when people process information about the punishment in a way that heightens their sense of imminent consequences. Successful information processing is reflected in the formation or revision of individuals' perceptions of sanction threats, including their perceptions about the certainty, severity, and celerity of punishment. With sanction threat perceptions as the central transmitter of punishment information, perceptual deterrence theory outlines two deterrence linkages or processes (see Pogarsky et al., 2004): a perceptual and a behavioral one.

According to the perceptual linkage, the legal (threat of) punishment can deter criminal behavior only indirectly by shaping perceptions of the certainty, severity, or celerity of punishment. How people form and update these sanction threat perceptions was outlined in Stafford and Warr's (1993) reconceptualization of deterrence theory. Stafford and Warr assume that individuals learn sanction threat perceptions through personal and vicarious (e.g., friends') experiences of punishment and punishment avoidance. Perceptions of punishment certainty are likely to increase when individuals are punished or observe others being punished, but should decrease through experiences of punishment avoidance. Perceptions of punishment severity and celerity are likely to be altered depending on how severe and swift the punishment is, but should not be affected by experiences of punishment avoidance.

According to the behavioral linkage, individuals who consider committing a crime may be deterred by (altered) sanction threat perceptions. To formalize this deterrent effect, perceptual deterrence research has often resorted to the use of subjective expected utility models (e.g., Matsueda et al., 2006; Piliavin et al., 1986). Inspired by Bentham (1789/2000), these rational choice models assume that deterrence happens when people abstain from illegal behavior because of its anticipated costs, including the perceived sanction threats, and instead engage in legal behaviors that are associated with higher expected utility (i.e., a higher benefit-cost balance).

A decade after this shift to focus on perception, empirical research relied on panel designs to collect repeated self-report data and investigate the two deterrence linkages simultaneously (e.g., Bishop, 1984; Hirtenlehner \& Wikström, 
2017; Matsueda et al., 2006; Minor \& Harry, 1982; Paternoster et al., 1985; Piliavin et al., 1986; Saltzman et al., 1982; Seddig et al., 2017). These panel studies explored how perceptions of detection or arrest certainty (hereinafter called risk perceptions) and criminal behavior affect each other over time. ${ }^{1}$ Most of the aforementioned studies found weak to moderate effects of criminal conduct on subsequent risk perceptions: Individuals who reported (more) crimes had subsequently lower risk perceptions than individuals who reported no (or less) criminal offending. This inverse relationship was dubbed an "experiential effect" (Saltzman et al., 1982), reflecting the idea that individuals learn through their criminal experiences that the detection or arrest risk is relatively low and downgrade their risk perceptions accordingly. The behavioral linkage, in contrast, received less support from the results of the panel studies: risk perceptions were often not or only weakly related to subsequent criminal offending.

The experiential effect estimates, however, do not necessarily reflect the proposed experiential learning process since they only show that criminal behavior is associated with lower risk perceptions. Their interpretation as experiential effects typically relies on the following assumptions (e.g., Hirtenlehner \& Wikström, 2017; Paternoster et al., 1985; Seddig et al., 2017): (1) individuals are rarely detected (or arrested) when committing their crimes; (2) individuals without (much) criminal experience tend to overestimate the detection risk; (3) when these inexperienced individuals begin committing crimes, they reduce their risk perceptions over time as they learn through (repeated) undetected offending that the actual detection risk is lower than first feared. Although plausible, almost no study so far has tested all three assumptions of this experiential argument (see Nagin, 1998). ${ }^{2}$

In the current article, we provide a thorough test of the experiential argument by subjecting its assumptions to closer scrutiny. To do so, we first review research on (1) the low detection risk for crime, (2) the overestimation of detection risk by individuals with no or little criminal experience, and (3) the decrease in risk perceptions due to (undetected) offending among individuals who had no or little previous criminal experience. After summarizing these assumptions in the form of hypotheses, the second part of the article empirically studies their validity using panel data from adolescents in Germany.

\section{State of Research}

\section{Low Detection Risk}

The assessment that most criminal offenses go undetected and unpunished is far from new. In the first treatises on criminal statistics, researchers like Adolphe

\footnotetext{
${ }^{1}$ Fewer perceptual studies investigated the perceived severity or celerity of punishment (for a review of this research, see Paternoster, 2018).

2 Only Lochner (2007) studied all three assumptions, but his data were limited in crucial aspects (see the "Overestimation of Detection Risk (by Individuals Inexperienced with Crime)" section).
} 
Quetelet (1842/2013) noted that their statistics included only those breaches of law that were recorded by official authorities (typically the police) and that there is a high "dark figure" of crime (Biderman \& Reiss, 1967, p. 2). The primary reasons why delinquent acts "stay in the dark" (i.e., are not recorded) are that they are not detected and recognized as a crime, that they are not reported to official authorities even if recognized (e.g., by a victim), or that they are not recorded by the official authorities even if reported (Black, 1970).

To empirically estimate how large the actual risk of detection by the police (as key official authority) is, two types of information are necessary: the total number of crimes in which the police detected or identified the offender $\left(\mathrm{Crimes}_{\text {Detected }}\right)$ and the total number of crimes committed $\left(\right.$ Crimes $\left._{\text {Total }}\right)$. A detection rate (DR) can then be computed by dividing the former by the latter number (DR $=$ Crimes $_{\text {Detected }} /$ Crimes $_{\text {Total }}$ ). Due to the filtering processes mentioned above (detection, reporting, recording), official crime statistics severely underestimate the criminal activity in a population and thus overestimate the true detection rate (Apel, 2013). Official data are, therefore, not a reliable source for the computation of a detection risk (but see Ahlberg \& Knutsson, 1990).

To solve the problem of crime underestimation, researchers can rely on selfreports. Under the assumption that individuals disclose their criminal and detection experiences honestly and accurately, ${ }^{3}$ self-report data allow for a more reliable estimate of the detection rate. Most previous perceptual panel studies, although based on self-reports, lacked data on detection and thus could not construct a detection rate (Hirtenlehner \& Wikström, 2017). Other previous self-report studies, however, collected both crime and detection data and computed detection rates (per offense type) in one of two ways: either by dividing the total number of crimes detected by the police according to the offenders by the total number of reported crimes or by calculating the proportion of offenders who reported that they were detected by the police when committing their last criminal offense. ${ }^{4}$

The latter procedure was applied in the Second International Self-Report Delinquency Study (ISRD-2), which contains what is probably the most extensive source of self-reported information on crime and detection. The ISRD-2 collected data from 12- to 15-year-old juveniles in 31 (mainly European) countries between 2006 and 2008. Enzmann's (2012) analysis of the ISRD-2 data indicates that police detection is a rare phenomenon, with juveniles typically reporting detection in only one out of ten offenses or even less frequently. More serious offenses with a victim had higher detection rates (e.g., assault, burglary, or theft of a car) than minor or "victimless" offenses (e.g., drug dealing, shoplifting, or vandalism). Other self-report research has reported similar or even lower detection rates that varied similarly

\footnotetext{
3 Thornberry and Krohn (2000) noted that self-reports of crimes and detections (arrests) are reasonably reliable and valid, but that there is substantial underreporting. However, as long as both types of information are underreported to a similar degree, a detection rate will be relatively unbiased. Findings of Köllisch and Oberwittler (2004) confirm that respondents who underreport do so with respect to both their criminal activity and their contact with the police.

${ }^{4}$ The latter procedure works if this last offense can be treated as a sample of all offenses committed (Enzmann, 2012).
} 
across offenses (e.g., Erickson \& Empey, 1963; Lochner, 2007; Wikström et al., 2012; Williams \& Gold, 1972). ${ }^{5}$

\section{Overestimation of Detection Risk (by Individuals Inexperienced with Crime)}

In a second step, the experiential argument suggests that risk overestimation by individuals with no or little experience in violating the law is a major reason for the inverse relationship between criminal offending and risk perceptions. Researchers have often assumed that the inexperienced may overestimate the detection risk because they base their perceptions (mainly) on media-created stereotypes of criminals (e.g., Geerken \& Gove, 1975; Matsueda et al., 2006; Paternoster, 2018). In the movies, on television, and in the news, criminals are usually caught and arrested. The media thus convey the impression that the legal system is more efficient in detecting crimes than it actually is. Although both individuals with no or little experience and experienced offenders are affected by this indirect information, the latter also have more direct information from their own personal experiences with criminal behavior. This personal knowledge allows them to assess the detection risk more accurately (Geerken \& Gove, 1975). Those with no or little criminal experience must rely on more indirect information and thus tend to be surrounded by what Tittle (1980, p. 67) coined a "shell of illusion," which is a "perceptual system incorporating assumptions that terrible consequences will follow from violation of the rules."

There are two strands of empirical research providing some insights into the assumption of risk overestimation. The first strand, lacking data on detections, has simply explored whether experienced offenders and individuals with no or little experience in offending differ in their risk perceptions. In line with the experiential argument, this research has consistently found that individuals with no or little criminal experience assess the detection risk as higher than (more) experienced offenders (e.g., Bishop, 1984; Paternoster et al., 1985; Saltzman et al., 1982). However, without calibrating the perceived risk with a detection rate, this literature cannot determine whether this correlation exists because the detection risk is overestimated by the inexperienced or because experienced offenders underestimate it.

The second strand of research has compared whether individual risk perceptions align with the actual detection rates in a given population. To our knowledge, only one of these so-called calibration studies compared risk perceptions with arrest rates that were calculated accurately based on self-report data (see the "Low Detection Risk" section). In a study on adolescents and young adults from the USA, Lochner (2007) found that individuals substantially overestimated the arrest risk on average. In line with the experiential argument, non-offenders overestimated the risk to a higher degree than recent offenders. However, Lochner did not rely on "lifetime" offending data but only compared individuals who had and had not recently committed offenses. He therefore could not distinguish between individuals who had no or

\footnotetext{
5 Similar arrest rates were also calculated by other scholars who divided official arrest data by selfreported criminal behavior (e.g., Elliott, 1995; Nguyen \& Reuter, 2012).
} 
little experience in violating the law and individuals who had more prior experience at a point in the more distant past. The latter, however, should have already reduced their risk perceptions through their prior offending, according to the experiential argument. Lochner's calibration study, hence, can be seen as a conservative test of the overestimation thesis.

Finally, a comparison of the low detection rates reported in the "Low Detection Risk" section with risk perception estimates provided by other (external) studies (Anwar \& Loughran, 2011; Matsueda et al., 2006; Schulz, 2014) further supports the overestimation thesis. Average estimates of the detection or arrest risk are typically much higher than the low police detection or arrest rates reported above, and most studies report particularly high risk estimates among individuals with no or little experience in violating the law.

\section{Decrease of Risk Perceptions due to (Undetected) Offending}

The final and most crucial assumption of the experiential argument is that individuals with no or little criminal experience decrease their risk perceptions when they begin committing crimes, as they learn through undetected offending that the detection risk is lower than first feared. This argument aligns with Stafford and Warr's (1993) hypothesis that experiences of punishment avoidance should generally lead to a lowering of risk perceptions, as "successful" (undetected) offenders learn through experience that detection is relatively unlikely. It is also consistent with Bayesian updating models (e.g., Anwar \& Loughran, 2011; Lochner, 2007; Matsueda et al., 2006) that consider detection (avoidance) experiences as signals that people process to update their initial (i.e., prior) risk perception. According to these models, detection avoidance should lead to a decreased subsequent (i.e., posterior) risk perception compared to one's prior risk perception.

Furthermore, one strand of the experiential literature discussed whether the "novelty" of the criminal behavior or the perceptual "naivete" of individuals is the more critical facilitator of the experiential effect (see Minor \& Harry, 1982; Paternoster et al., 1985). The term novelty effect suggests that the downgrading of risk perceptions due to criminal offending happens mainly (or is especially strong) among those with no or little previous involvement in criminal behavior. For them, involvement in illegal activity is a new experience, providing novel information that should lead to a more substantial alteration of risk perceptions than committing one more in a long series of offenses. The term naiveté effect, in contrast, refers to the importance of the level of prior risk perceptions for the updating process. It assumes that only (or mainly) "naïve" individuals, i.e., those who have high (overestimated) risk estimates prior to committing crimes, lower their risk perceptions substantially after violating the law. Individuals who already possess low and thus more accurate risk estimates are in little need of adjusting their perceptions to more realistic levels.

Many perceptual panel studies have not adequately explored the risk perception changes proposed in the experiential argument. This is because they utilized their data in ways that were not designed to explore effects within individuals over time but rather estimated differences in risk perceptions between individuals (e.g., 
Bishop, 1984; Minor \& Harry, 1982; Piliavin et al., 1986; Saltzman et al., 1982; Seddig et al., 2017). The few studies that have concentrated on intra-individual changes were typically hampered by including information on criminal offending only over the last few months or years (e.g., Hirtenlehner \& Wikström, 2017; Lochner, 2007; van Veen \& Sattler, 2018). These studies consistently found that the more people had been involved in recent deviant or criminal activity, the lower their subsequent risk perceptions were. However, due to the lack of "lifetime" offending information, these studies could not accurately examine the updating process outlined in the experiential argument, which begins with the assumption of risk overestimation by those with no (or little) criminal experience (and not just by those with no recent criminal experience).

So far, Schulz (2014) is the only researcher to have used fixed effects models to calculate within estimates to analyze how risk perceptions of individuals with no previous criminal experience change when they begin committing crimes. In a subsample of British adolescents and young adults with no prior criminal experience, she found evidence of the proposed updating process. The individuals who started committing crimes during the period under examination lowered their risk perceptions. However, a weakness of her analysis is her categorization of the criminal offending variable. She categorized periods in which a person stopped committing crimes (after having initially started) in the same category with periods in which they committed a small number of crimes (fewer than three). This procedure prevented her from exploring whether individuals revert to prior risk perception levels when they stop offending and whether renewed criminal offending after a temporary cessation of criminal activity has similar downgrading effects. Such a finding could challenge the assumption that the novelty of criminal behavior is a primary source for the updating process.

Two other studies have utilized residual change score models to explore whether novelty or naiveté effects are the primary driver of the proposed experiential learning process. While the findings of Paternoster et al. (1985) were relatively inconsistent, the analysis of Pogarsky et al. (2004) based on US high school students produced more clear-cut results. It showed more support for the naiveté than for the novelty effect (see also Minor \& Harry, 1982). After committing crimes, a substantial lowering of risk perceptions was only found among individuals with high prior risk perceptions and not among those with lower risk estimates. Changes in risk perceptions due to offending, in contrast, did not differ significantly between individuals with no, moderate, or extensive previous criminal experience.

\section{Current Study and Hypotheses}

The current study revisits the experiential argument by investigating its three major underlying assumptions. Following on the research of Seddig et al. (2017), the current study uses data of a general sample of German juveniles to supplement the relatively scarce research outside of the USA that has explored processes of experiential learning (for notable exceptions, see Hirtenlehner \& Wikström, 2017; Schulz, 2014; Seddig et al., 2017; van Veen \& Sattler, 2018). In particular, the current study 
investigates the following hypotheses to explore the validity of the experiential argument:

H1: The risk of being detected by the police is low for most criminal offenses.

$\mathrm{H} 2$ : Individuals with no (or little) criminal experience overestimate the detection risk, whereas individuals with (more) criminal experience do not or do so to a lesser extent.

H3: When individuals begin committing crimes, they subsequently reduce their risk perceptions on average because they typically observe that the detection risk is much lower than first feared.

H3a: The less criminal experience individuals have before committing crimes, the more their risk perceptions are reduced due to criminal offending (novelty effect).

$\mathrm{H} 3 \mathrm{~b}$ : The higher the individuals estimate the detection risk before committing crimes, the more their risk perceptions are reduced due to criminal offending (naiveté effect).

\section{Methods}

\section{Data}

The current study relies on data from the study Crime in the modern City (CrimoC; Boers et al., 2010; Seddig \& Reinecke, 2017). The initial survey started in 2002 with 3,411 seventh graders at secondary schools in Duisburg, a town with a population of approximately 500,000 in the western part of Germany. Eight annual panel waves were conducted between 2002 and 2009, covering the period from early to late adolescence. Five additional biannual panel waves were conducted between 2011 and 2019 to cover the period from late adolescence to young adulthood. The students' ages ranged between approximately 13 and 30 years. Self-administered questionnaires were completed in the classroom up to the ninth grade. After leaving secondary school, participants were usually contacted by mail. If repeated attempts were unsuccessful, personal contacts were realized to conduct the interviews. Retention rates were between 82 and $91 \% .^{6}$

Four panel waves (2003 to 2006) covering the adolescents' age range were used for the analyses presented here. Only participants who fulfilled particular conditions were considered. First, we selected only juveniles who participated in at least two of the four panel waves. Second, we kept only observations with complete information on all the variables used for our analyses. Due to these conditions, our final sample includes 9,362 observations from 3,259 respondents. $^{7}$

\footnotetext{
${ }^{6}$ Details of the CrimoC study can be found at www.crimoc.org.

7 The first wave was not included because it lacked risk perception measures. Panel attrition led to some differences in variable distributions: more female participants, somewhat fewer respondents from lower secondary schools, and more from upper secondary schools in the panel data compared with the crosssectional data (Kleinke et al., 2020; Reinecke \& Weins, 2013).
} 


\section{Measures}

\section{Perceptions of Detection Risk}

As in Seddig et al. (2017), the measurement of our dependent variable, detection risk perceptions, is based on the respondents' assessments of their likelihood of being caught when committing four different types of criminal offenses (assault, burglary, shoplifting, and vandalism). Response categories were (0) very unlikely, (1) unlikely, (2) neither/nor, (3) likely, and (4) very likely. We constructed a general risk perception score by taking the mean across all four offense-specific perceptions (range: $0-4$ ).

\section{Self-Reported Criminal Offenses}

Our measure of criminal offending is also based on the items used in Seddig et al. (2017). It considers the juveniles' self-reported frequency of committing fifteen different criminal offenses over the last year. The crimes at hand were assault (no weapon), assault (with a weapon), bag-snatching, bicycle theft, burglary, fencing stolen goods, robbery, shoplifting, scratching, theft of a car, theft from a car, theft from a vending machine, theft (other), vandalism (graffiti), and vandalism (other). The reported frequencies of the various crime types were added to construct a recent total criminal offending score for each individual.

\section{Self-Reported Police Detections}

Detection information is based on the juveniles' reports of how many of the crimes they reported in the last year the police were aware of (for all 15 offense types mentioned above). By adding together the number of reported detections for each offense type, we constructed a score of recent total police detections for each individual. We relied on self-reports because the fact that people remembered having committed offenses and being detected should be more relevant for perceptual updating processes than the fact that they "objectively" committed crimes and were detected according to official sources.

\section{Detection Rates}

The calculation of detection rates is necessary to assess the first two assumptions of the experiential argument. As a reminder, a detection rate is computed by dividing the total number of detected crimes by the total number of crimes committed in a given population. For each of the 15 offense types, we calculated a detection rate by dividing the number of police detections (per offense) by the number of crimes (per offense) reported by the sample as a whole. Additionally, 
we computed a total detection rate encompassing all types of offenses by dividing all reported police detections by all reported crimes.

\section{Criminal Experience}

Our criminal experience measure, used as the primary independent variable in our updating analysis, combines data on recent criminal offending and criminal history. First, we categorized the recent total criminal offending score, which is highly skewed to the right, to diminish the effects of outliers (for a similar approach, see Matsueda et al., 2006; Schulz, 2014). The generated categories were the following: 0 crimes, 1-2 crimes, 3-9 crimes, and 10 or more crimes. To revise these categories further, we also considered juveniles' reports on whether they had ever committed any of the fifteen crimes to derive whether they really had no criminal experience (and not just no recent experience). Integrating this information, the criminal experience measure consists of the following categories: (0) never committed a crime, (1) committed a crime, but not in the past year, (2) 1-2 crimes in the past year, (3) 3-9 crimes in the past year, (4) 10 or more crimes in the past year. ${ }^{8}$

\section{Covariates}

The covariate selection reflects the importance of vicarious experiences with punishment (avoidance) for individual risk perceptions (Stafford \& Warr, 1993). As relevant sources of vicarious information, we selected deviant peer exposure, perceived neighborhood disorder, and time spent watching crime movies as key covariates. All these are discussed as factors that may present indirect sources of information about the risk of detection or punishment (e.g., Cook, 1980; Geerken \& Gove, 1975; Wilson \& Kelling, 1982). Exposure to a deviant peer group is an ordinal variable with the following categories: (0) spending no or little time with a peer group, (1) spending much time in low-deviant peer group activities, (2) spending much time in medium-deviant peer group activities, and (3) spending much time in high-deviant peer group activities. Perceived neighborhood disorder is a continuous variable ranging from -2 to 2 , with larger values indicating more perceived disorder. To assess the time spent watching crime movies, we considered respondents' reports on whether they watched crime movies (0) never, (1) rarely, (2) sometimes, (3) often, or (4) very often. ${ }^{9}$

\footnotetext{
${ }^{8}$ We recoded a substantial number of cases in which individuals reported in later panel waves that they had never committed any crimes, but had admitted offending in earlier waves to be in the category "committed a crime, but not in the past year." In a sensitivity analysis, we kept these inconsistencies, acknowledging that individuals may forget crimes committed further back in time. The results of this analysis resemble those presented in the current article (see online supplementary material). Additionally, we constructed another criminal experience variable considering personal police detections. However, as detection is a rare phenomenon in the given sample, categories including detection information were small and thus estimation uncertainty too high to be informative. Besides having low power, this alternative specification produced similar results (see online supplementary material).

${ }^{9}$ For the specific items that were used to calculate all variables included in the fixed effects models, see Table A1 in the Appendix.
} 


\section{Analytical Procedure}

The first analytical step assesses whether the detection rates in the given sample are low. To do this, we report offense-specific and total detection rates. We use the panel data in a pooled way to construct these rates, as we want to give an overview of the actual police detection risk over the whole period of adolescence (and not for a specific panel wave).

The second analytical step explores whether individuals who have never committed a crime overestimate the risk of detection. To do this, we compare whether individuals with no criminal experience have higher risk perceptions than those with criminal experience. Unfortunately, our risk perception measures cannot be reliably transformed to a probability scale. Thus, we refrain from formally testing the difference between the detection rates and risk perceptions. We, instead, use descriptive statistics to explore whether individuals with no criminal experience overestimate the detection risk and whether they do so to a larger extent than individuals with criminal experience. ${ }^{10}$

Finally, the third analytical step investigates whether individuals reduce their risk perceptions when they learn through "successful" (undetected) offending that the detection risk is lower than first feared. To analyze this updating process, we rely on fixed effects models (Allison, 2009). These models adjust for all of the respondents' observed and unobserved time-stable characteristics. By investigating within-person changes (rather than differences between respondents), fixed effects models allow us to examine how, for example, changes in criminal experiences among respondents are associated with changes in their perceived detection risks. To study whether the criminal experiences lead to the risk perception updating outlined in the experiential argument, we utilize the criminal experience measure as an independent variable and the general risk perception score as the dependent variable. In a second step, we also include other covariates to account for potential confounding. ${ }^{11}$ Our fixed effects models have the following structure:

$$
\left(Y_{i t}-\bar{Y}_{i}\right)=\left(X_{i t}-\bar{X}_{i}\right)+\left(\varepsilon_{i t}-\bar{\varepsilon}_{i}\right)
$$

In the analysis, differences to the within-person mean of perceived detection risk $\bar{Y}_{i}$ at time point $t$ are regressed on differences to the within-person mean in the covariates $\bar{X}_{i}$. Since unobserved heterogeneity among individuals is completely eliminated by the reduction to intra-individual changes, the risk of over- or

\footnotetext{
${ }^{10}$ In an additional analysis, we transformed the risk perception values into POMP scores. These scores represent the percentage of maximum possible values and, as percentages, could be compared much more directly with the detection rates. However, we think that such comparison may give the false impression that we can analytically assess the alignment of our (ordinal-scaled) risk perception measures with the detection rates in a proper way. To prevent such an impression, we present the POMP scores only in the online supplementary material.

11 To pick up potential year shocks resulting from underlying unobservable systematic differences between observed time units (period effects), all fixed effects models also control for the current panel wave.
} 
Table 1 Total and offensespecific detection rates

\begin{tabular}{llll}
\hline Offense & $\begin{array}{l}\text { Police } \\
\text { detec- } \\
\text { tions }\end{array}$ & Crimes & Detection rate \\
\hline Bag-snatching & 0 & 106 & $0.0 \%$ \\
Theft (other) & 5 & 723 & $0.7 \%$ \\
Bicycle theft & 9 & 1,047 & $0.9 \%$ \\
Fencing stolen goods & 24 & 2,240 & $1.1 \%$ \\
Vandalism (graffiti) & 89 & 7,379 & $1.2 \%$ \\
Vandalism (other) & 65 & 4,845 & $1.3 \%$ \\
Robbery & 15 & 1,076 & $1.4 \%$ \\
Theft from a car & 4 & 252 & $1.6 \%$ \\
Theft from a vending machine & 10 & 452 & $2.2 \%$ \\
Shoplifting & 148 & 6,560 & $2.3 \%$ \\
Assault (no weapon) & 165 & 5,393 & $3.1 \%$ \\
Burglary & 20 & 552 & $3.6 \%$ \\
Scratching & 194 & 5,137 & $3.8 \%$ \\
Theft of a car & 13 & 208 & $6.3 \%$ \\
Assault (with weapon) & 34 & 514 & $6.6 \%$ \\
Total & 795 & 36,484 & $2.2 \%$ \\
\hline
\end{tabular}

underestimating effects as well as causal misinterpretations is significantly reduced in fixed effects models compared to competing methods. However, this advantage is countered by relatively large standard errors and thus less efficient estimates, which are caused by the lack of consideration of time-constant variables in fixed effects models (Allison, 2009). From our point of view, however, it is crucial to report results that have a lower risk of being biased by unobserved factors and more closely mirror the proposed experiential learning process that unfolds over time within individuals.

\section{Results}

\section{Low Detection Risk}

The calculated detection rates support the assumption that the detection risk is low for most criminal offenses (see Table 1). Overall, the juveniles reported that the police detected only $2.2 \%$ (795) of their 36,484 crimes. ${ }^{12}$ This very low estimate is generally consistent with previous research, although some studies have reported somewhat higher detection rates (see Enzmann, 2012; Erickson \& Empey, 1963;

\footnotetext{
12 The detection rates were computed for observations with complete information on all variables included in the updating analysis. If we loosen this condition and also use information from observations with missing data, the overall detection risk increases to $3.0 \%$ (see online supplementary material).
} 
Lochner, 2007; Wikström et al., 2012; Williams \& Gold, 1972). The ranking of the detection rates by offense types also aligns with previous research: more serious offenses that include a victim have higher detection rates (e.g., assault with a weapon: $6.6 \%$; theft of a car: $6.3 \%$ ) than relatively minor or "victimless" offenses (e.g., bicycle theft: $0.9 \%$; shoplifting: $2.3 \%$; theft from a vending machine: $2.2 \%$; vandalism (graffiti): $1.2 \%$ ).

\section{Overestimation of Detection Risk (by Individuals Inexperienced with Crime)}

In this subsection, we explore whether the respondents (with no criminal experience) estimated the detection risk accurately or if they overestimated it. Risk estimates were only collected and thus reported for a subset of criminal offenses. As a reminder, risk perception scores range from 0 to 4 . To assess the detection risk accurately as (very) low, individuals should have scores between 0 (very unlikely) and 1 (unlikely).

The results show that the juveniles tended to overestimate the detection risk but ranked the risk for different crime types in roughly correct order (see Table 2, column 2). The mean of the general risk perception score is 2.18 for the full sample, indicating that juveniles, on average, perceived the general detection risk as neither likely nor unlikely $(=2)$. This risk assessment does not align with the actual detection rates, according to which the detection risk was very low. Thus, the juveniles overestimated the risk of detection on average. However, they were relatively accurate in ordering the detection risk across different kinds of criminal offenses. In line with the actual detection rates (see Table 1), they assessed the risk of detection for vandalism (mean $=1.58$ ) as substantially more unlikely than for burglary (mean = 2.91). The risks for shoplifting and assault were somewhere in between.

However, to empirically investigate the experiential argument, we must inspect the risk perceptions for individuals with no (or little) criminal experience who are expected to be particularly prone to overestimation compared to their counterparts

Table 2 Descriptive statistics of general and offense-specific risk perceptions

\begin{tabular}{|c|c|c|c|c|c|c|c|}
\hline \multirow[t]{2}{*}{ Risk perceptions by offense } & \multicolumn{2}{|c|}{ Full sample } & \multicolumn{2}{|c|}{$\begin{array}{l}\text { No criminal } \\
\text { experience }\end{array}$} & \multicolumn{2}{|c|}{$\begin{array}{l}\text { Some criminal } \\
\text { experience }\end{array}$} & \multirow[t]{2}{*}{$\begin{array}{l}\text { Mean }_{1}-\text { Mean }_{2} \\
{[\mathrm{SE}]}\end{array}$} \\
\hline & Mean & SD & Mean $_{1}$ & SD & $\operatorname{Mean}_{2}$ & $\mathrm{SD}$ & \\
\hline Vandalism (graffiti) & 1.58 & 1.42 & 1.65 & 1.42 & 1.21 & 1.32 & $0.44[0.04]$ \\
\hline Assault (no weapon) & 1.97 & 1.32 & 2.10 & 1.30 & 1.65 & 1.30 & $0.45[0.03]$ \\
\hline Shoplifting & 2.29 & 1.31 & 2.39 & 1.32 & 2.14 & 1.28 & $0.26[0.03]$ \\
\hline Burglary & 2.91 & 1.29 & 2.93 & 1.29 & 2.66 & 1.31 & $0.27[0.06]$ \\
\hline Total & 2.18 & 0.99 & 2.35 & 1.07 & 2.08 & 0.92 & $0.27[0.03]$ \\
\hline
\end{tabular}

Note: the number of person-observations of those with no and some criminal experience differs across offense types and the numbers reported in the following apply to the total offenses: $n_{\text {Obs }}$ (full sample) $=$ 9,$362 ; n_{\text {Obs }}$ (no criminal experience $)=3,646 ; n_{\text {Obs }}$ (some criminal experience $)=5,716$; mean differences and their cluster-robust standard errors were calculated with regression models (all corresponding $p$ values $<0.001)$ 
with (more) criminal experience. The calculated risk perceptions support this assumption. On average, the inexperienced individuals perceived the detection risk to be higher than individuals who had reported at least one previous criminal offense (see Table 2, columns 4 and 6). This overestimation is true for all offense-specific risk estimates and the general risk perception score, with a mean of 2.35 among the inexperienced and only 2.08 among the experienced. However, even if most of the inexperienced overestimated the detection risk (73\% with values of at least 2; $34 \%$ with values of at least 3 ), a substantial portion had much lower (and more realistic) risk perceptions (11\% with values between 0 and 1). This considerable risk perception variation is also reflected in the relatively large standard deviation of 1.07 (offense-specific perceptions vary even more; see Table 1, column 5). Among those who had been involved in criminal activities before, the variation is only somewhat smaller and only for some offenses (see Table 2, column 7). This lower risk perception variation is mainly because experienced offenders much less often assessed the general detection risk to be very high (only $19 \%$ with values of at least 3 ).

\section{Decrease of Risk Perceptions due to (Undetected) Offending}

We finally present the results of various fixed effects models to assess the main experiential argument that individuals (with no criminal experience) decrease their risk perceptions when they start committing crimes (see Table 3$).{ }^{13}$ Overall, these models support the outlined updating process.

Model 1 includes only individual criminal experience as an independent variable. It suggests that the more recent illegal activity people are involved in, the more they reduce their risk perceptions relative to periods before having ever committed a crime (i.e., the reference category). This inverse relationship between criminal involvement and risk perceptions followed a monotonic pattern: More offenses were associated with lower risk perceptions (e.g., $>=10$ recent crimes: $\beta=-0.37[-0.49$ $-0.25])$. The model, furthermore, indicates that even if a person had not recently (i.e., in the last 12 months) committed a crime but did so at some point in the past, they may still had a slightly reduced risk perception (no recent crime: $\beta=-0.07$ $[-0.160 .03])$. However, the estimate is too uncertain to claim whether such a small "sustained" risk perception decrease holds in the population.

The idea of a sustained risk perception decrease is also called into question by the results of Model 2, which includes the other covariates besides personal criminal experience. Criminal involvement has a more modest effect on risk perceptions in this model specification than in the first. Only if individuals committed at least a minimal number of offenses, did they have substantially reduced risk perceptions (3-9 recent crimes: $\beta=-0.13[-0.25-0.01]$; $>=10$ recent crimes: $\beta=-0.26$ $[-0.39-0.13])$ compared with a period in which they had no criminal experience.

\footnotetext{
13 In addition to the models presented, we also computed a null model to explore how much variation in general risk perceptions is within and between individuals. Derived from this null model, the intraclass correlation (ICC) of 0.31 suggests that risk perceptions vary substantially between and within individuals.
} 
Table 3 Modeling the updating process: changes in general risk perceptions

\begin{tabular}{|c|c|c|c|c|c|c|}
\hline \multirow[t]{2}{*}{ Predictor } & \multicolumn{2}{|c|}{ Model 1} & \multicolumn{2}{|c|}{ Model 2} & \multicolumn{2}{|c|}{ Model 3} \\
\hline & $\beta$ & $95 \%-\mathrm{CI}$ & $\beta$ & $95 \%-\mathrm{CI}$ & $\beta$ & $95 \%$-CI \\
\hline
\end{tabular}

Criminal experience $(\mathrm{CrEx})$

(ref.: never crime)

No recent crime

1-2 recent crimes

3-9 recent crimes

$\geq 10$ recent crimes

CrEx X Perceived risk in

times without offending

(ref.: never crime)

No rec. crime $X$ Low risk

1-2 rec. crimes $X$ Low

risk

3-9 rec. crimes X Low

risk

$\geq 10$ rec. crimes $X$ Low

risk

$$
\left.\begin{array}{lllllllll}
-0.07 & {[-0.16} & 0.03] & 0.02 & {[-0.08} & 0.12] & -0.01 & {[-0.12} & 0.10] \\
-0.13 & {[-0.24} & -0.01] & -0.06 & {[-0.17} & 0.06] & -0.47 & {[-0.61} & -0.34] \\
-0.20 & {[-0.32} & -0.09] & -0.13 & {[-0.25} & -0.01] & -0.51 & {[-0.67} & -0.36] \\
-0.37 & {[-0.49} & -0.25] & -0.26 & {[-0.39} & -0.13] & -0.69 & {[-0.86} & -0.52
\end{array}\right]
$$

Peer group exposure

(ref.: no or little exposure)

Low-deviant

Medium-deviant

High-deviant

Neighborhood disorder

Watch crime movies

(ref.: never)

Rarely

Sometimes

Often

\begin{tabular}{|c|c|c|c|c|c|c|c|c|c|}
\hline 2004 & & & & -0.16 & {$[-0.22$} & $-0.11]$ & -0.17 & {$[-0.23$} & $-0.12]$ \\
\hline 2005 & & & & -0.07 & {$[-0.13$} & $-0.02]$ & -0.08 & {$[-0.14$} & $-0.02]$ \\
\hline 2006 & & & & -0.16 & {$[-0.22$} & $-0.10]$ & -0.17 & {$[-0.23$} & $-0.10]$ \\
\hline Constant & 2.27 & {$[2.21$} & $2.33]$ & 2.33 & {$[2.24$} & $2.43]$ & 2.36 & {$[2.27$} & $2.45]$ \\
\hline Persons & & 3,259 & & & 3,259 & & & 2,858 & \\
\hline Observations & & 9,362 & & & 9,362 & & & 8,497 & \\
\hline
\end{tabular}

Very often

Panel wave

(ref.: 2003)

Note: Unstandardized regression coefficients of fixed effects models with cluster-robust confidence intervals (CI)

$\left.\begin{array}{lll}0.09 & {[-0.11} & 0.30\end{array}\right]$

$$
\left.\begin{array}{llllll}
-0.04 & {[-0.09} & 0.02] & -0.04 & {[-0.09} & 0.01] \\
-0.18 & {[-0.25} & -0.10] & -0.19 & {[-0.27} & -0.11] \\
-0.26 & {[-0.38} & -0.14] & -0.26 & {[-0.40} & -0.12] \\
0.02 & {[-0.02} & 0.07] & 0.05 & {[0.00} & 0.09
\end{array}\right]
$$

$$
\begin{aligned}
& \left.\begin{array}{llllll}
0.01 & {[-0.06} & 0.09
\end{array}\right] \quad 0.01 \quad\left[\begin{array}{lll}
-0.07 & 0.09
\end{array}\right] \\
& 0.05 \quad\left[\begin{array}{lllll}
-0.04 & 0.13
\end{array}\right] \quad 0.05 \quad\left[\begin{array}{lll}
-0.04 & 0.13
\end{array}\right] \\
& 0.08 \quad\left[\begin{array}{lllll}
-0.01 & 0.18
\end{array}\right] \quad 0.07 \quad\left[\begin{array}{lll}
-0.03 & 0.17
\end{array}\right]
\end{aligned}
$$

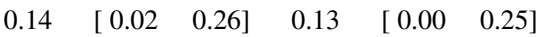


Furthermore, the same person's risk perceptions do not seem to differ much depending on whether they had never committed a crime or whether they had, but not in the past 12 months (no recent crime: $\beta=0.02[-0.080 .12]$ ). This finding suggests that individuals who decrease their risk perceptions directly after committing (many) crimes seem to return to their initial risk perception level when the crime experiences recede further into the past. When they then commit crimes again, they reduce their risk perceptions to a similar degree as before. This latter finding poses a challenge to the novelty effect assumption that it is especially first-time criminal experience that leads to risk perception updating.

The other covariates included in the model are only partly related to the risk perceptions as hypothesized in the literature. First, in line with vicarious learning (Cook, 1980; Stafford \& Warr, 1993), the more an individual was exposed to a deviant peer group, the lower their risk perceptions. Second, and at odds with the suggestion of broken windows theory that neighborhood decay may signal a low detection risk (Wilson \& Kelling, 1982), perceived neighborhood disorder had no substantial effects on individual risk assessments. Third, and as expected (Geerken \& Gove, 1975; Matsueda et al., 2006), frequent viewing of crime movies was associated with increased risk perceptions.

Finally, we present the results of Model 3, which has the same specification as Model 2 but also includes an additional interaction term between a newly generated variable and criminal experience to analyze the naiveté effect. The new variable is time-invariant and binary and could be coined "risk perception level in times of non-offending." It distinguishes between individuals who had, on average, risk perceptions between 0 and 2 in periods in which they committed no crimes and individuals who had values between 2 and 4 . The estimates for the interaction term are significant for all criminal experience categories except for the category "no recent crime" (see Table 3). This result suggests that the two groups differ substantially in how they update their risk perceptions when they commit criminal offenses but that both groups return to prior risk estimate levels when they stop committing crimes (see Figure 1). Whereas those with low risk perceptions (in times without offending) do not change or instead increase their risk perceptions when they become involved in criminal activity, those with high risk perceptions do the opposite. They substantially reduce their risk estimates, and they reduce them the most when they commit a large number of crimes $(>=10$ recent crimes: $\beta=-0.69[-0.86-0.52])$. This finding of differential updating conditional on "initial" risk perceptions (i.e., the average risk perception level in times of non-offending) lends some support to the naiveté effect.

\section{Discussion}

The current study assessed the validity of the experiential argument by exploring its three underlying assumptions. Overall, our evaluation strengthens the experiential argument but also poses some intriguing challenges. The following finding supports the first hypothesis (H1): The total detection rate in the given sample was very low, with only $2.2 \%$ of all crimes detected by the police. Offense-specific detection rates, 

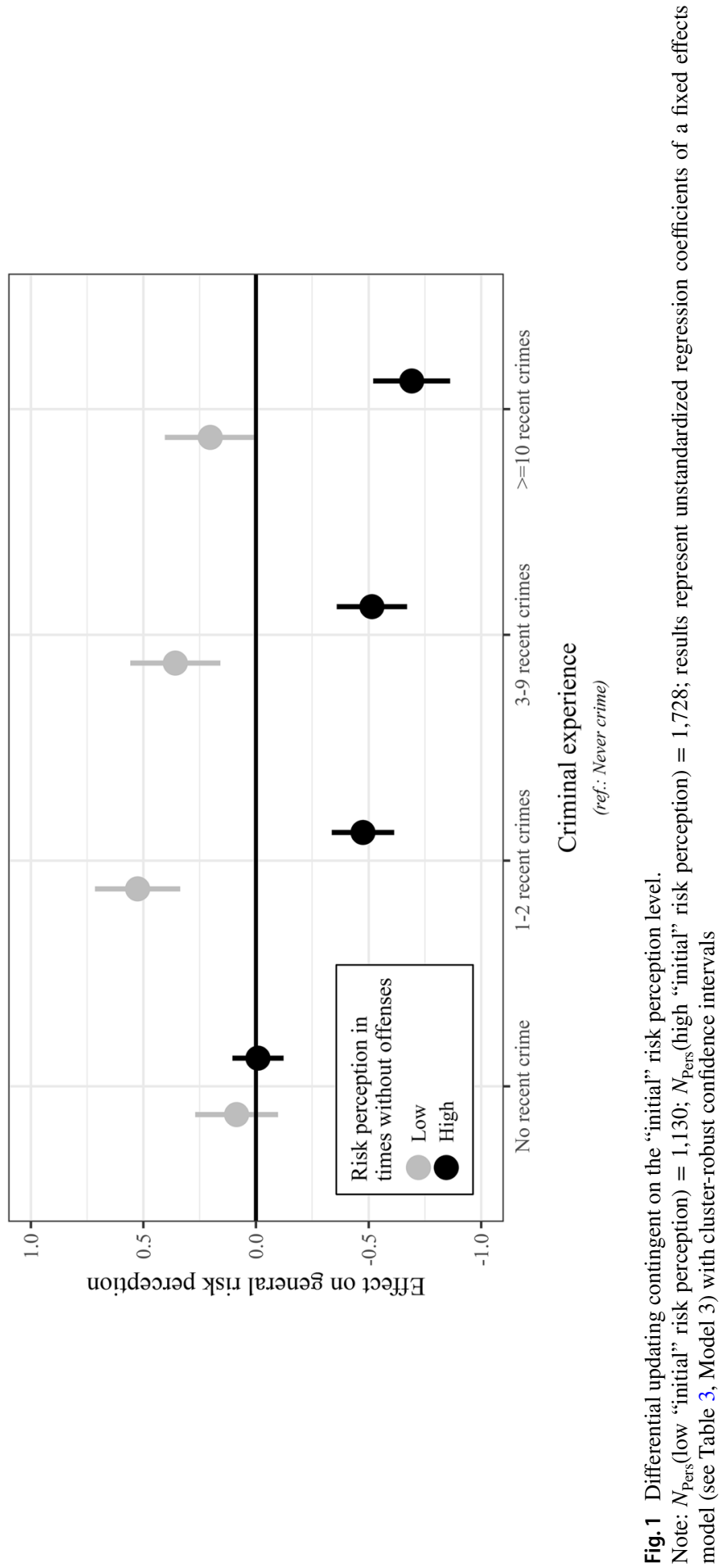
furthermore, were all below $10 \%$. These detection rates align with previous research, although tending toward the lower bound of the previously reported rates (Enzmann, 2012; Erickson \& Empey, 1963; Lochner, 2007; Wikström et al., 2012; Williams \& Gold, 1972). Overall, current and previous findings support the assumption of a low risk of police detection for criminal offending.

The second assumption of the experiential argument was only partially supported by the current study. In line with Hypothesis $\mathrm{H} 2$, the findings indicate that individuals overestimate the detection risk on average and that those without criminal experience do so to a greater extent than those who possess some criminal experience. Offense-specific perceptions furthermore suggest that individuals rank the detection risk for various crime types roughly in the correct order. Both results correspond to findings reported by Lochner (2007). Thomas et al. (2018, p. 81) produced supporting evidence that "individuals are locally coherent in the rank order of arrest risk among different crime types." The finding of risk overestimation is further corroborated by comparing the low detection rates with the high risk perceptions consistently reported in other (external) studies (e.g., Matsueda et al., 2006; Schulz, 2014). However, although our analysis seems to support the overestimation thesis, additional explorations highlight the extensive variation in risk perceptions. Most strikingly, a substantial portion of juveniles without criminal experience estimated the detection risk accurately as being (very) low. These individuals hardly fit the experiential argument since they do not overestimate the detection risk and hence cannot downgrade their risk perceptions any further by starting to commit undetected crimes.

Finally, the third assumption of the experiential argument, that individuals without (much) criminal experience lower their risk perceptions when they start committing crimes, was also partly supported by the current study. With our fixed effect models, we analyzed how risk perceptions changed depending on intra-individual changes in criminal offending. In line with Schulz's (2014) findings, the detection risk was assessed as substantially lower when an individual had recently been involved in repeated criminal activity than when the same individual had never committed any crime before. This finding is generally supportive of the updating process outlined in the experiential argument (see H3).

However, the current study also produced a surprising finding not observed in prior research: Risk perceptions did not differ substantially over time depending on whether a person had never committed a crime before or whether they had, but not in the past 12 months. This finding indicates that after individuals reduce their risk perceptions to more realistic levels, they do not stabilize their estimates but instead fall back to their initial overestimated levels when they stop offending. When they start to commit crimes again, they again reduce their risk perceptions to a similar degree. This finding poses some challenge to the experiential argument and especially to the assumption of the novelty effect that perceptions that were previously influenced by relevant information should be less malleable in the future (see H3a).

There has been little other research to date showing that people may return to overestimation (or into the "shell of illusion") when they stop committing crimes (however, see Lochner, 2007; Paternoster et al., 1985). One exception is Lochner (2007, p. 455), who interpreted the results of one of his model specifications to 
suggest that there is "little persistence in the effects of new information on reported beliefs." He noted that individuals seem to have baseline risk beliefs to which they revert back to in times in which they gather no or little direct information. His finding aligns with our results and may be explained in the following ways: First, individuals may have short memories of (unfulfilled) risks (e.g., Lochner, 2007; Pogarsky et al., 2004). Criminal experiences without harmful consequences (e.g., detection) may thus fade from memory when they recede into the past. This forgetting may be especially relevant for illegal behavior since (most) individuals may want to suppress memories of immoral activity to preserve a positive, coherent self-concept (Fawcett \& Hulbert, 2020). ${ }^{14}$ Second, more recent information, even if indirect, proves to be more important for risk estimation than more distant information, even it is more direct (e.g., Lochner, 2007; Pogarsky et al., 2004). From this perspective, a return to higher risk perceptions may be explained by the "overwriting" of old personal information with newer (less accurate) vicarious information (e.g., provided by the media). ${ }^{15}$ Finally, perceptions of one's detection risk may be grounded in one's self-confidence in committing crimes without being apprehended (Loughran et al., 2013). The more frequently an individual commits crimes, the more confident they may become that they can avoid detection and punishment. When individuals then stop committing crimes, this self-confidence may wane over time as they lack recent experiences that indicate that they can still avoid detection.

Whereas the latter finding sheds doubt on the novelty effect, our study strengthens the naiveté effect. It shows that individuals update differently when they commit crimes depending on their initial risk perception level in times without criminal offenses. In line with the naiveté effect (see H3b), the lowering of risk perceptions due to criminal offending can be only observed among those who had relatively high risk perceptions in times in which they did not commit a crime. This finding is consistent with the few other studies that also found evidence for the naiveté effect while providing little or at best inconsistent support for the novelty effect (e.g., Minor \& Harry, 1982; Pogarsky et al., 2004). However, in the current study, it is striking that individuals who had low initial risk perceptions (in times without criminal offenses) even increased these perceptions after committing crimes. In their early study on this topic, Paternoster et al. (1985, p. 419) considered these kinds of "re-equilibrating" effects in times without criminal offenses but offered no decisive explanation for them. It seems reasonable to assume, however, that vicarious information may also play a role in these upgrading processes. Individuals who generally estimate the risk of detection as relatively low may be affected in their lives by continuous vicarious experiences that provide a realistic view of detection risk. When they become involved in criminal activities, this indirect information is typically confirmed. Still,

\footnotetext{
14 The thesis of forgetting seems to be supported by the substantial number of juveniles who reported criminal offenses in previous waves but reported in later waves that they had never committed any of the crimes at hand.

15 Comparing Model 1 and 2 lends some evidence supporting this explanation. Through the inclusion of covariates (see Model 2), the difference in risk perceptions between the reference category "never crime" and the category "no recent crime" disappears. Bringing in vicarious information, the covariates thus may explain part of the "bouncing-back" process when a person stops committing crime.
} 
they may fear at some point that their "streak of luck" (i.e., committing crimes without being apprehended) may come to an end. This feeling of being due to be caught may lead them to adjust their risk perceptions upward. Such a "resetting" of risk perceptions was already hypothesized for punished offenders in the opposite direction (i.e., they adjust their risk perceptions downward after being punished, see Pogarsky \& Piquero, 2003).

\section{Limitations}

Although providing essential support and challenges to the experiential argument, the findings presented above have to be seen in the light of three notable limitations of the current study. First, although we call our measures "perceptions" in line with previous research, Wikström (2008) rightly noted that such measures actually reflect relatively abstract risk assessments: perceptions are situational and cannot be measured by such contextless risk evaluations. However, Wikström also acknowledges that general risk assessments should be related to perceived risks and should therefore give at least some insights into how respondents perceive the detection risk in real-life circumstances. Additionally, our general risk assessments are not collected in ways that are easily scalable to align with the detection rates. Thus, we abstained from analytically comparing both measures. Future research should replicate our findings with probabilityscaled risk assessment measures (for such measures, see Lochner, 2007; Schulz, 2014). ${ }^{16}$ This research should also include perceptual measures that specifically refer to the perceived risk of detection by the police. Otherwise, this research is hampered, like ours, by calibrating perceived risks of general detection with police detection rates.

Second, although the fixed effects models used in the current study have distinct advantages over other methods used in previous perceptual updating research, they are not a panacea in terms of the temporal ordering of the intra-individual changes. Even if our models are specified such that changes in criminal activity influence changes in risk perceptions, they are not able to actually ensure that the influence operates (exclusively) in the specified direction. Instead, our results might also (partially) reflect a (deterrence) influence of risk perceptions on criminal activity. However, two aspects increase our confidence that our results can be interpreted as experiential effects rather than deterrence

\footnotetext{
16 We agree with Apel (2013, p. 94) that "probabilistic measures of risk perceptions [...] seem to be the most desirable relative to other response formats" (e.g., because they allow calibrating risk perceptions with detection rates). We, however, do not think that our results would change much if we had applied such measures instead. There are two reasons for our assessment: first, respondents seem to think about detection risk verbally and not in fine-grained numeric terms, limiting the additional value of probability scales (Roche et al., 2020). Second, existing studies with numerical or probability-scaled measures produced results in line with our main findings: (1) individuals overestimate the detection risk (Lochner, 2007); (2) individuals with criminal experience assess the likelihood of detection as higher than those inexperienced with crime (e.g., Paternoster et al., 1985; Schulz, 2014); (3) individuals lower their detection risk estimates after they start committing crimes (Schulz, 2014).
} 
effects. On the one hand, previous research that tried to disentangle the two effects typically found much more substantial experiential effects (e.g., Hirtenlehner \& Wikström, 2017; Saltzman et al., 1982; Seddig et al., 2017). Thus, even if our results represent a mixture of both effects, experiential effects should be the primary contributor. On the other hand, the reference periods of our two key measures are consistent with our interpretation: while data on criminal activity were collected retrospectively (offenses in the past 12 months), data on risk perceptions referred to the time of data collection. Assuming that respondents can adequately process temporal cues in the questionnaires, our results should reflect pure experiential effects.

Third, our fixed effect models explain only a small portion of the intra-individual variation in risk perceptions (up to 5.4\%). Such lack of explanatory power is true for most previous risk updating studies and was highlighted as a "dirty little secret in deterrence research" (Paternoster, 2010, p. 808). Confronted with the fact that personal and vicarious experiences with punishment (avoidance) explain only a small portion of the risk perception variation, the deterrence literature offers two pathways to develop more powerful explanatory models. On the one hand, research should consider situational determinants of risk perceptions (Apel, 2013). Recent research suggests that heuristics such as anchoring or availability may play a prominent role in forming risk perceptions (Pogarsky et al., 2017) and thus should be considered alongside experiential or vicarious learning processes. On the other hand, literature on differential deterrability highlights that updating and deterrence processes may vary across situations and persons. For updating, this literature has provided some first evidence that the strength of updating differs across individuals who vary in their previous criminal involvement, selfcontrol abilities, and personal morals (e.g., Anwar \& Loughran, 2011; Pogarsky et al., 2005; Schulz, 2014). Future research should follow these two promising paths to develop more sophisticated models of the formation and change of risk perceptions.

\section{Policy Implications}

Despite these limitations, the current study seems to offer some critical implications for criminal justice policy. It indicates that a low risk of police detection is responsible for juveniles lowering their detection risk assessments when they start committing crimes. According to deterrence theory, such a decrease in risk perceptions is startling because it should lead to more future criminal offending by those whose crimes go undetected (and those who witnessed their impunity). Confronted with similar results, Matsueda et al. (2006, p. 117) concluded that this finding "underscores the importance of early interventions, occurring before delinquent careers develop and risk estimates decline." Rather than calling for criminal justice agents to implement measures dramatically increasing the risk of detection, however, Matsueda and colleagues proposed the establishment of early educational programs emphasizing the long-run risk of detection in criminal careers. We agree with their proposal and their assessment that 
disproportionate measures would be required to increase the police detection rate substantially.

Furthermore, two aspects may reassure policymakers and legal authorities that the lowering of risk perceptions may be less detrimental than it seems at first glance and that strong reactions would be unwarranted. First, if it is true that only more recent criminal experiences are responsible for the formation of risk perceptions, this is positive news. When former offenders temporarily or permanently stop committing crimes, they will typically return to their prior, mostly overestimated, risk assessment levels. This return to overestimation (or into the "shell of illusion") may in turn hinder their involvement in future illegal activity. Second, according to perceptual deterrence theory, deterrence consists of two processes. Seen from this broader perspective, the lowering of risk perceptions (perceptual linkage) may be less dramatic because the evidence for the behavioral linkage is relatively modest. Many perceptual studies found no or only relatively modest effects of risk perceptions on criminal offending (for reviews, see Nagin, 1998; Paternoster, 2018; Wikström, 2008). However, if risk perceptions have relatively little influence on future delinquency, then their change through prior undetected offending should lead to relatively low increases in criminal offending.

\section{Conclusion}

The current study produced several findings that support the experiential argument: first, juveniles are rarely detected by the police when committing crimes. Second, juveniles overestimate the risk of detection on average, and individuals with no criminal experience overestimate this risk to a larger extent. Third, when juveniles start committing (relatively large numbers of) crimes, they reduce their risk perceptions. Fourth, in line with the naiveté effect, this reduction occurs primarily among those individuals who estimate the detection risk as high in periods in which they are not committing crimes. However, our research also yielded an intriguing finding that challenges the experiential argument in its current form. This finding suggests that people seem to return to initial overestimated risk levels when they stop committing crimes. If they start committing crimes again, they again reduce their risk estimates to a similar degree. This finding challenges the assumption of the novelty effect that once a person develops more accurate perceptions through first criminal experiences, perceptual changes brought about through new information should be less likely and less extensive. Future research should investigate this bouncing-back effect through episodes of non-offending in more detail. The experiential argument may eventually need to be refined to account for the short-lived nature of criminal experience effects. In this refined version, the novelty effect may give way to the "ephemerality effect," which would state that only (or especially) recent criminal activity is relevant for the lowering of risk perceptions, while older criminal experience loses its perceptual impact over time. 


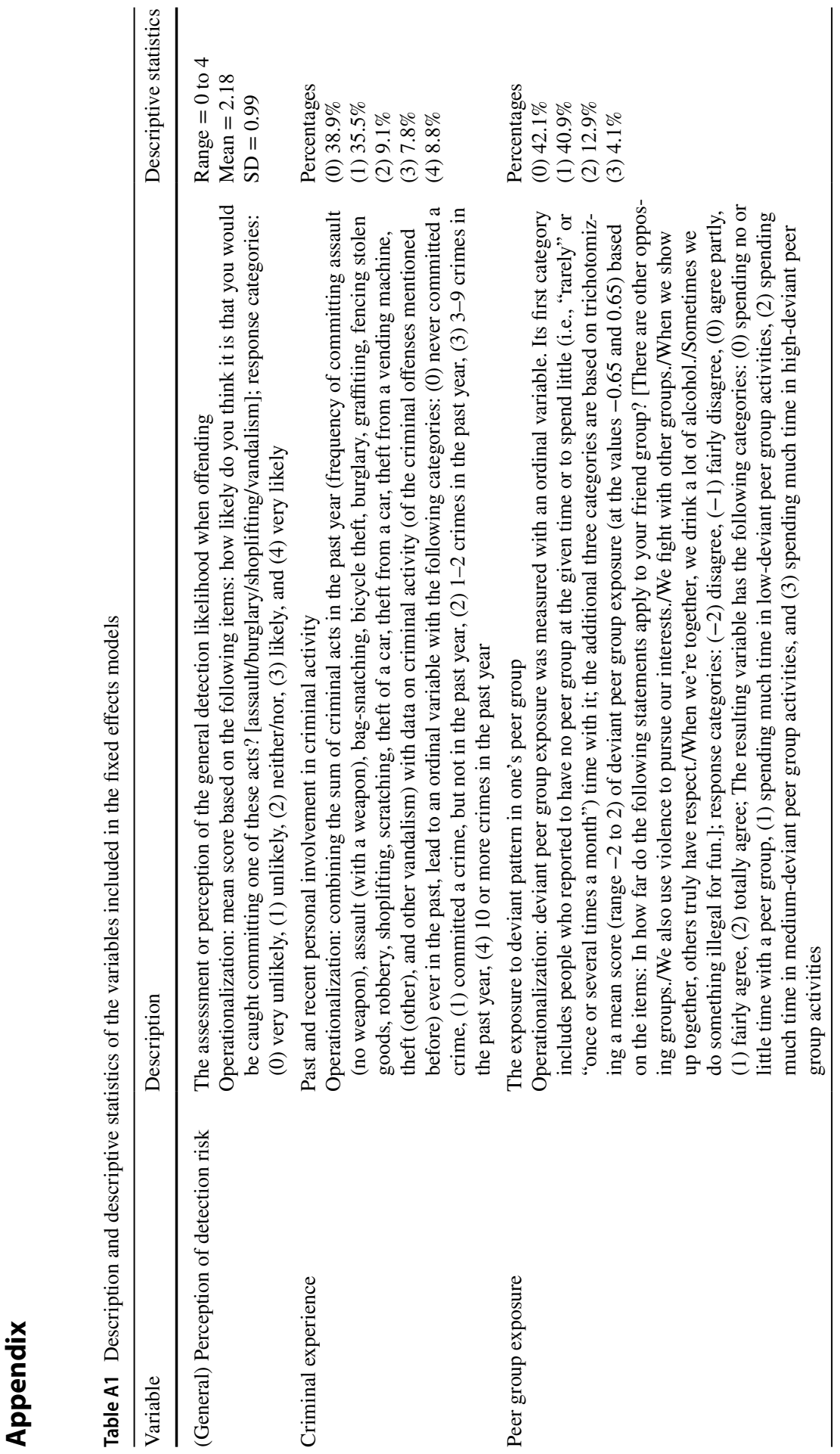




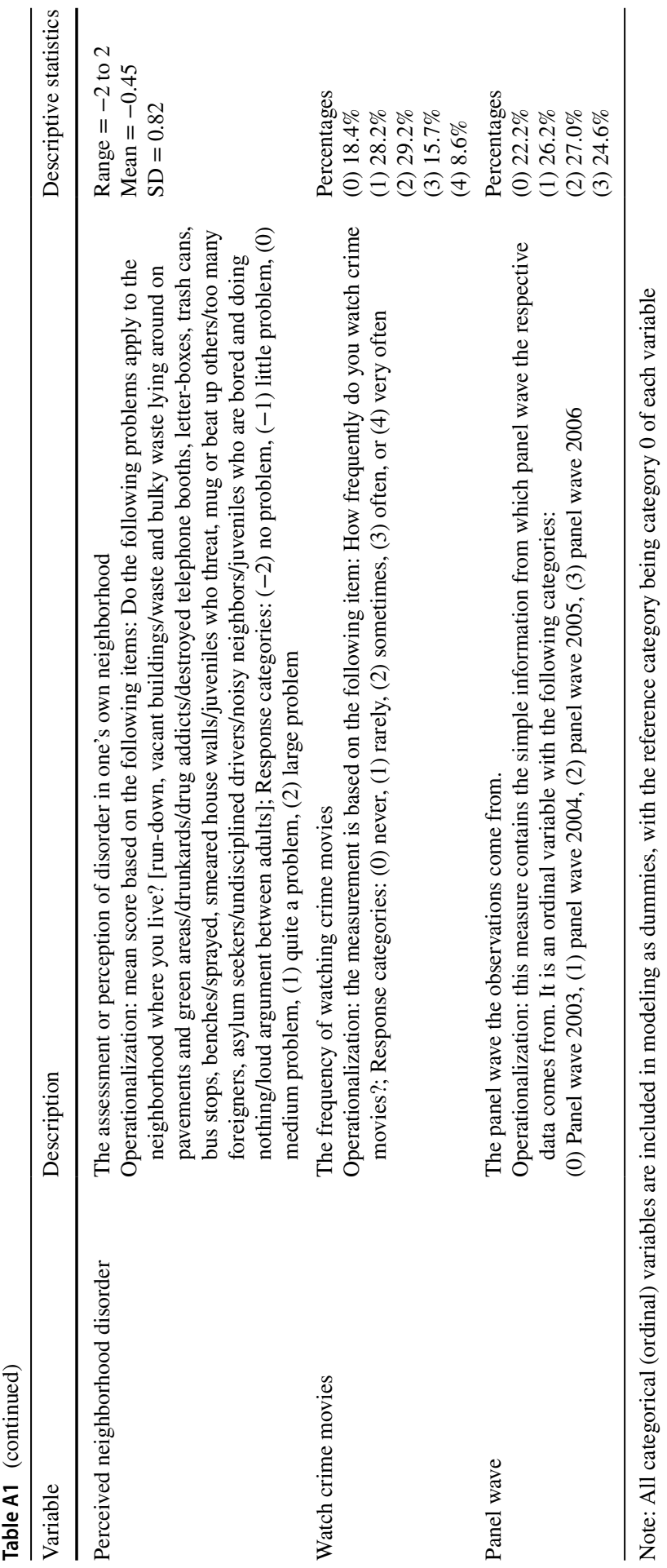


Supplementary Information The online version contains supplementary material available at https://doi. org/10.1007/s40865-021-00186-4.

Acknowledgements We thank Christina Bentrup, Klaus Boers, Franziska Hasselbach, Leon Lohrmann, Marcus Scharff, and Hannah Wittbrodt for the time they spent discussing an earlier draft of our paper. Additionally, we would like to thank the anonymous reviewers for their helpful comments on this article.

Funding Open Access funding enabled and organized by Projekt DEAL. The study Crime in the modern City (CrimoC) was fully funded by the German Research Foundation (Deutsche Forschungsgemeinschaft; DFG; grant number: BO 1234/8-10).

\section{Declarations}

Disclaimer Points of view or opinions in this document are those of the authors and do not necessarily represent the official position or policies of the funding agencies.

Conflict of Interest The authors declare no competing interests.

Open Access This article is licensed under a Creative Commons Attribution 4.0 International License, which permits use, sharing, adaptation, distribution and reproduction in any medium or format, as long as you give appropriate credit to the original author(s) and the source, provide a link to the Creative Commons licence, and indicate if changes were made. The images or other third party material in this article are included in the article's Creative Commons licence, unless indicated otherwise in a credit line to the material. If material is not included in the article's Creative Commons licence and your intended use is not permitted by statutory regulation or exceeds the permitted use, you will need to obtain permission directly from the copyright holder. To view a copy of this licence, visit http://creativecommons.org/licen ses/by/4.0/.

\section{References}

Ahlberg, J., \& Knutsson, J. (1990). The risk of detection. Journal of Quantitative Criminology, 6(1), 117-130. https://doi.org/10.1007/BF01065293

Allison, P. D. (2009). Fixed effects regression models (Vol. 160). Sage.

Anwar, S., \& Loughran, T. A. (2011). Testing a Bayesian learning theory of deterrence among serious juvenile offenders. Criminology, 49(3), 667-698. https://doi.org/10.1111/j.1745-9125.2011.00233.x

Apel, R. J. (2013). Sanctions, perceptions, and crime: Implications for criminal deterrence. Journal of Quantitative Criminology, 29(1), 67-101. https://doi.org/10.1007/s10940-012-9170-1

Beccaria, C. (1872). An essay on crimes and punishments. W.C. Little \& Co. (Original work published 1764).

Bentham, J. (2000). An introduction to the principles of morals and legislation. Batoche Books. (Original work published 1789)

Biderman, A. D., \& Reiss, A. J. (1967). On exploring the "dark figure" of crime. The Annals of the American Academy of Political and Social Science, 374, 1-15.

Bishop, D. M. (1984). Deterrence: A panel analysis. Justice Quarterly, 1(3), 311-328. https://doi.org/10. 1080/07418828400088181

Black, D. J. (1970). Production of crime rates. American Sociological Review, 35(4), 733-748. https:// doi.org/10.2307/2093948

Boers, K., Reinecke, J., Seddig, D., \& Mariotti, L. (2010). Explaining the development of adolescent violent delinquency. European Journal of Criminology, 7(6), 499-520. https://doi.org/10.1177/14773 70810376572

Cook, P. J. (1980). Research in criminal deterrence: Laying the groundwork for the second decade. Crime and Justice, 2, 211-268. 
Elliott, D. (1995). Lies, damn lies and arrest statistics [The Sutherland Award Presentation]. The American Society of Criminology Meetings, Boston.

Enzmann, D. (2012). Social responses to offending. In J. Junger-Tas, I. H. Marshall, D. Enzmann, M. Killias, M. Steketee, \& B. Gruszczynska (Eds.), The many faces of youth crime: Contrasting theoretical perspectives on juvenile delinquency across countries and cultures (pp. 143-182). Springer. https://doi.org/10.1007/978-1-4419-9455-4_6

Erickson, M. L., \& Empey, L. T. (1963). Court records, undetected delinquency and decision-making. Journal of Criminal Law, Criminology and Police Science, 54(4), 456-469.

Fawcett, J. M., \& Hulbert, J. C. (2020). The many faces of forgetting: Toward a constructive view of forgetting in everyday life. Journal of Applied Research in Memory and Cognition, 9(1), 1-18. https:// doi.org/10.1016/j.jarmac.2019.11.002

Geerken, M. R., \& Gove, W. R. (1975). Deterrence: Some theoretical considerations. Law \& Society Review, 9(3), 497-514. https://doi.org/10.2307/3053169

Hirtenlehner, H., \& Wikström, P.-O. H. (2017). Experience or deterrence? Revisiting an old but neglected issue. European Journal of Criminology, 14(4), 485-502. https://doi.org/10.1177/ 1477370816671750

Kleinke, K., Reinecke, J., \& Weins, C. (2020). The development of delinquency during adolescence: A comparison of missing data techniques revisited. Quality \& Quantity. https://doi.org/10.1007/ s11135-020-01030-5

Köllisch, T., \& Oberwittler, D. (2004). Wie ehrlich berichten männliche Jugendliche über ihr delinquentes Verhalten? Ergebnisse einer externen Validierung [How honestly do male adolescents report their delinquent behaviour? Results of an external validation of self-reported delinquency]. Kölner Zeitschrift für Soziologie und Sozialpsychologie, 56(4), 708-735. https://doi. org/10.1007/s11577-004-0110-4

Lochner, L. (2007). Individual perceptions of the criminal justice system. American Economic Review, 97(1), 444-460. https://doi.org/10.1257/aer.97.1.444

Loughran, T. A., Paternoster, R., Piquero, A. R., \& Fagan, J. (2013). "A good man always knows his limitations": The role of overconfidence in criminal offending. Journal of Research in Crime and Delinquency, 50(3), 327-358. https://doi.org/10.1177/0022427812459649

Matsueda, R. L., Kreager, D. A., \& Huizinga, D. (2006). Deterring delinquents: A rational choice model of theft and violence. American Sociological Review, 71(1), 95-122. https://doi.org/10. 1177/000312240607100105

Minor, W. W., \& Harry, J. (1982). Deterrent and experiential effects in perceptual deterrence research: A replication and extension. Journal of Research in Crime and Delinquency, 19(2), 190-203. https://doi.org/10.1177/002242788201900204

Nagin, D. S. (1998). Criminal deterrence research at the outset of the twenty-first century. Crime and Justice, 23, 1-42.

Nguyen, H., \& Reuter, P. (2012). How risky is marijuana possession? Considering the role of age, race, and gender. Crime \& Delinquency, 58(6), 879-910. https://doi.org/10.1177/0011128712 461122

Paternoster, R. (2010). How much do we really know about criminal deterrence? Journal of Criminal Law and Criminology, 100(3), 765-824.

Paternoster, R. (2018). Perceptual deterrence theory. In D. S. Nagin, F. T. Cullen, \& C. L. Jonson (Eds.), Deterrence, choice, and crime (pp. 81-106). Routledge.

Paternoster, R., Saltzman, L. E., Waldo, G. P., \& Chiricos, T. G. (1985). Assessments of risk and behavioral experience: An exploratory study of change. Criminology, 23(3), 417-436. https:// doi.org/10.1111/j.1745-9125.1985.tb00348.x

Piliavin, I., Gartner, R., Thornton, C., \& Matsueda, R. L. (1986). Crime, deterrence, and rational choice. American Sociological Review, 51(1), 101. https://doi.org/10.2307/2095480

Pogarsky, G., Kim, K., \& Paternoster, R. (2005). Perceptual change in the National Youth Survey: Lessons for deterrence theory and offender decision-making. Justice Quarterly, 22(1), 1-29.

Pogarsky, G., \& Piquero, A. R. (2003). Can punishment encourage offending? Investigating the "resetting" effect. Journal of Research in Crime and Delinquency, 40(1), 95-120. https://doi.org/10. $1177 / 0022427802239255$

Pogarsky, G., Piquero, A. R., \& Paternoster, R. (2004). Modeling change in perceptions about sanction threats: The neglected linkage in deterrence theory. Journal of Quantitative Criminology, 20(4), 343-369. https://doi.org/10.1007/s10940-004-5868-z 
Pogarsky, G., Roche, S. P., \& Pickett, J. T. (2017). Heuristics and biases, rational choice, and sanction perceptions. Criminology, 55(1), 85-111. https://doi.org/10.1111/1745-9125.12129

Quetelet, L. A. J. (2013). A treatise on man and the development of his faculties (T. Smibert, Ed.; R. Knox, Trans.). Cambridge University Press. https://doi.org/10.1017/CBO9781139864909 (Original work published 1842)

Reinecke, J., \& Weins, C. (2013). The development of delinquency during adolescence: A comparison of missing data techniques. Quality \& Quantity, 47(6), 3319-3334. https://doi.org/10.1007/ s11135-012-9721-4

Roche, S. P., Pickett, J. T., Intravia, J., \& Thompson, A. J. (2020). On the measurement of subjective apprehension risk. Criminal Justice Review. https://doi.org/10.1177/0734016820978827

Saltzman, L. E., Paternoster, R., Waldo, G. P., \& Chiricos, T. G. (1982). Deterrent and experiential effects: The problem of causal order in perceptual deterrence research. Journal of Research in Crime and Delinquency, 19(2), 172-189.

Schulz, S. (2014). Individual differences in the deterrence process: Which individuals learn (most) from their offending experiences? Journal of Quantitative Criminology, 30(2), 215-236. https://doi.org/ 10.1007/s10940-013-9201-6

Seddig, D., Hirtenlehner, H., \& Reinecke, J. (2017). Beeinflussen Sanktionsrisikoeinschätzungen das delinquente Handeln junger Menschen oder ist es umgekehrt? Befunde einer deutschen Längsschnittuntersuchung [Does the perceived risk of sanctions influence juvenile delinquent behavior or vice versa: Results from a German longitudinal study]. Kölner Zeitschrift für Soziologie und Sozialpsychologie, 69(2), 259-282. https://doi.org/10.1007/s11577-017-0448-z

Seddig, D., \& Reinecke, J. (2017). Exploration and explanation of adolescent self-reported delinquency trajectories in the Crimoc study. In A. A. J. Blokland \& V. van der Geest (Eds.), The Routledge international handbook of life-course criminology (pp. 159-178). Routledge.

Stafford, M. C., \& Warr, M. (1993). A reconceptualization of general and specific deterrence. Journal of Research in Crime and Delinquency, 30(2), 123-135. https://doi.org/10.1177/002242789303000 2001

Thornberry, T. P., \& Krohn, M. D. (2000). The self-report method for measuring delinquency and crime. In D. Duffee (Ed.), Measurement and analysis of crime and justice (Vol. 4, pp. 33-83) US Department of Justice.

Tittle, C. R. (1980). Sanctions and social deviance: The question of deterrence. Praeger.

van Veen, F., \& Sattler, S. (2018). Modeling updating of perceived detection risk: The role of personal experience, peers, deterrence policies, and impulsivity. Deviant Behavior, 3(1), 1-21. https://doi. org/10.1080/01639625.2018.1559409

Waldo, G. P., \& Chiricos, T. G. (1972). Perceived penal sanction and self-reported criminality: A neglected approach to deterrence research. Social Problems, 19(4), 522-540. https://doi.org/10. $2307 / 799929$

Wikström, P.-O. H. (2008). Deterrence and deterrence experiences: Preventing crime through the threat of punishment. In S. G. Shoham, O. Beck, \& M. Kett (Eds.), International handbook of penology and criminal justice (pp. 345-378). CRC Press.

Wikström, P.-O. H., Oberwittler, D., Treiber, K., \& Hardie, B. (2012). Breaking rules: The social and situational dynamics of young people's urban crime. Oxford University Press.

Williams, J. R., \& Gold, M. (1972). From delinquent behavior to official delinquency. Social Problems, 20(2), 209-229. https://doi.org/10.2307/799615

Wilson, J. Q., \& Kelling, G. L. (1982). Broken windows: The police and neighborhood safety. The Atlantic Monthly, 249(3), 29-38.

Publisher's Note Springer Nature remains neutral with regard to jurisdictional claims in published maps and institutional affiliations. 


\section{Authors and Affiliations}

\section{Florian Kaiser ${ }^{1}$ (D) $\cdot$ Björn Huss $^{2}$ (D) . Jost Reinecke ${ }^{3}$}

1 Institute of Criminal Law and Criminology, University of Münster, Bispinghof 24/25, 48143 Münster, Germany

2 German Centre for Higher Education Research and Science Studies (DZHW) / Sociology Department, University of Hanover, Schneiderberg 50, 30167 Hanover, Germany

3 Faculty of Sociology, Bielefeld University, Universitätsstraße 24, 33615 Bielefeld, Germany 